\title{
Rhythmic analysis and quantitative measures: the essence of rhythm as temporal patterning
}

Michela Russo

University of Paris 8/UMR 7023-C.N.R.S., France

https://doi.org/10.36505/ExLing-2008/02/0048/000107

\begin{abstract}
A comparison of Standard Italian and Southern Italian dialects is carried out using acoustic measures related to structural properties: Vowel-interval and consonantal inter-vowel-interval durations are used to obtain rhythmic measures based on a number of approach. Italian is usually considered to be 'syllabletimed'. The structural features found in the dialects offer support for a divergence from the traditional assumption of syllable-timing. Rhythm measures are calculated according to Ramus at al. 1999, Grabe-Low 2002, Barry et al. 2003, Russo-Barry to appear. In agreement with predictions derived from phonological observation, the results of the measures show a 'rhythm plot' in which the 'Pairwise Variability Indices (PVIs) place the Italian dialect speakers nearer to the stress-timed' languages than traditional typology statements would lead one to expect
\end{abstract}

Key words: language typology, Italian dialects, rhythmic values

\section{What differences are there between the languages?}

In traditional views of rhythmic typology the rhythmic classification of a language was considered a given 'primitive', an inherent property of the language. In contrast, more recent studies see it as an emergent property, a product of both the phonotatics of the language and phonetic processes in production (Dauer 1987). Syllable complexity, possibly vocalic and consonantal length distinctions, stress-dependent vowel reduction and the propensity for phonetic vocalic and consonantal reduction processes ('schwa-isation', weakening and elision, etc.) during speech are considered contributory factors to the rhythm of an utterance, and via this to the general rhythmic impression of a language. Critically, rhythm not only becomes measurable, as a speech phenomenon rather than an inherent language property, but it also necessarily becomes a continuous rather than a categorical property.

Italian is usually considered a 'syllable-timed' language: it has a relatively simple (CV-dominated) basic syllable structure, no phonological vowel length opposition and no phonological vowel reduction. On the other hand, it has a consonantal length distinction, and pronounced allophonic tonic-vowel lengthening. Phonetic and phonological evidence supports the interpretation of Southern Italian dialects (Ischia, Capri, and the dialect of Pozzuoli, near Naples) as a stress-timed language. Distributional

ExLing 2008: Proceedings of 2nd Tutorial and Research Workshop on Experimental Linguistics, 25-27 August 2008, Athens, Greece 
observations and durational measurements of tauto-and heterosyllabic VC sequences show that make a strictly syllable-timed rhythmic structure untenable. The structural features found in the dialects that offer support for a divergence from this traditional assumption are: a) Long vowels or long diphthongs in closed syllables; b) Neutralisation of vowel timbre in unstressed syllable; c) Loss of unstressed vowels. Although much of the dialect observations place the stress-timing evidence at the systemic rather than the realisational level, the non-systemic, 'performance' evidence points in the same direction.

\section{Rhythm measures}

Rhythm measures are calculated according to Ramus et al. 1999, Grabe-Low 2002, Barry et al. 2003, Russo-Barry to appear. The Ramus measures are (i) the proportion of vowels in the interpause streches ips $(\% \mathrm{~V})$, (ii) the standard deviation of the Vowel duration in the ips $(\Delta \mathrm{V})$ and (iii) the standard deviation of the intervocalic consonantal interval $(\Delta \mathrm{C})$. The Grabe and Low measures correspond in essence to the Ramus variability measures, but are calculated in pairwise steps through the ips rather than globally across the ips. They are therefore called 'Pairwise Variability Indices' (PVIs).

(i) Non-normalized consonantal PVI:

$$
r P V I=\left[\sum_{k=1}^{m-1}\left|d_{k}-d_{k+1}\right| /(m-1)\right]
$$

(ii) Normalized vowel PVI (for vowels to correct for tempo fluctuations):

$$
{ }^{n} P V I=100 \times\left[\sum_{k=1}^{\lceil m-1}\left|\frac{d_{k}-d_{k+1}}{\left(d_{k}+d_{k+1}\right) / 2}\right| /(m-1)\right\rfloor
$$

The difference (i) between consecutive vowels and (ii) between consecutive intervocalic intervals are averaged over the ips, giving a vocalic and consonantal variability measure. In the case of the vowel intervals, the difference is related to the sum of the two vowels. This 'normalisation' is claimed to be necessary (and possible) for the vowel intervals in order to counteract shifts in tempo because vowels vary more than consonants with tempo, and there is never more than one vowel in a vowel interval.

Corpora had been segmented and labelled, providing the segmental identities and durations which form the basis of the rhythm measures. Pauses, hesitations and other interruptions had also been annotated, so it was possible to identify prosodically uninterrupted 'inter-pause stretches' (ips): 
Table 1. Ramus $(\% \mathrm{~V}, \Delta \mathrm{V}, \Delta \mathrm{C})$ and Grabe-Low (PVI-V, PVI-C) rhythm measures for the Naples, Pisa and German speaker groups.

\begin{tabular}{|l|l|l|l|l|l|}
\hline Lang.group & $\% \mathrm{~V}$ & $\Delta \mathrm{V}$ & $\Delta \mathrm{C}$ & $\mathrm{PVI}-\mathrm{V}$ & $\mathrm{PVI}-\mathrm{C}$ \\
\hline Naples & 54.2 & 59.8 & 51.5 & 39.2 & 56.4 \\
\hline Pisa & 55.1 & 65.4 & 51.0 & 43.0 & 58.9 \\
\hline German & 42.0 & 42.2 & 64.5 & 55.0 & 65.1 \\
\hline
\end{tabular}

The Italian here consists of semi-spontaneous speech recordings from the AVIP/API regional database (Archivio Varietà Italiano Parlato, ftp://ftp.cirass.unina.it - Map-Task dialogues) and the German is the Kiel Corpora of read and spontaneous speech (IPDS 1994, 1995).

As showed from the average group values given in Table 1, what is most striking about the measures is the much higher vowel variability of the Italian speakers. They are further from the Spanish values found in previous studies even than English and German.These may lie in the amount of speech material, in the type of speech material, or in the selection of speakers. Furthermore, we give here measures for 10 fluent sections of spontaneous speech from the Neapolitan dialect of Ischia (Forío, a total of $33.62 \mathrm{sec}$ ). The average PVI scores for one speaker is: Raw PVI (Consonant interval) 52.52, Normalized PVI (Vowel interval) 55.98. The average percentage vocalic interval in the utterances is $54.9 \%$. Compared to our earlier data and to data in the literature these measures are different to some extent, but only in the consonantal measure: the $\% \mathrm{~V}$ value of $54 \%$ is clearly equivalent to the Italian values we got for Bari, Pisa and Napoli and much higher than any of the German or Bulgarian values (they never reached 50\%, even at the fastest tempo, Barry et al. 2003). Our values for Bari, Pisa and Napoli are (from the AVIP/API corpus): Raw PVI-C Bari 61.6, Pisa 58.9, Napoli 56.4; Norm V-PVI Bari 41.6, Pisa 43.0, Napoli 39.2. So the speaker consonant variability is lower (there is no support for 'stress timing'), but the vowel variability is considerably higher (pushing the vowels away from syllable timing). For comparison, our German values were: Raw PVI-C German 68; Norm PVI-V - German 55. The values from Grabe-Low 2002 are: German 59.7/55.3, English 64.1/57.2, French 50.4/43.5, Spanish $57.7 / 29.7$. In terms of text-dependent variation in the values, Grabe-Low 2002 publish the following values for 3 different parts of their material: PVIC German 52.1/57.0/55.9; English 65.6/65.0/54.4; French 49.3/49.7/44.3; Spanish 60.3/56.9/54.7; PVI-V German 57.6/65.3/58.7; English 55.2/53.6/56.1; French 39.4/38.7/42.0; Spanish 26.4/27.7/26.0. We compare these values with the variation over 10 utterances of the dialectal speaker's. Raw PVI-C: 56.4, 37.1, 44.6, 36.7, 54.6, 71.7, 55.3, 44.8, 49.7, 74.3; Norm PVI-V: 45.2, 52.7, 63.7, 64.5, 51.3, 55.6, 60.2, 65.7, 51.2, 49.7. The values 
above show a 'rhythm plot' in which the PVI-V groups the dialectal speaker with 'stress-timed' languages against the traditional typology expectation.

\section{Acknowledgements}

Grateful thanks to William John Barry, Caren Brinckmann, Bistra Andreeva and Anja Moos for processing the labelled data used for the analysis.

\section{References}

Barry, W.J. and Russo, M. 2003. Measuring rhythm. Is it separable from speech rate? In Mettouchi, A. and Ferré, G. (eds.), AAI Workshop, Prosodic Interfaces, 15-20. Nantes, Université de Nantes, UFR Lettres et Langage, AAI.

Barry, W.J. and Russo, M. 2004. Isocronia oggettiva o soggettiva? Relazioni tra tempo articolatorio e quantificazione ritmica. In Albano Leoni, F., Cutugno, F., Pettorino, M. and Savy, R. (eds.), Il parlato Italiano, cdrom A02. Napoli, D'Auria.

Barry, W.J., Andreeva, B., Russo, M., Dimitrova, S. and Kostadinova, T. 2003. Do Rhythm Measures Tell us Anything about Language Type?. In Solé, M., Recasens, D. and Romero, J. (eds.), Proc. of the 15th Intern. Congress of Phonetic Sciences, 2693-2696. Barcelona: Causal Productions Pty Ltd.

Dauer, M.R. 1987. Phonetic and phonological components of language rhythm. In Proc. Of 11th Intern. Congress of Phonetic Sciences. Tallinn, 447-450. Estonia: U.S.S.R. / Academy of Science of the Estonian S.S.R., vol. 5.

Grabe, E. and Low, E.L. 2002. Durational Variability in Speech and the Rhythm Class Hypothesis. In Gussenhoven, C. and Warner, N. (eds.), Papers in Laboratory Phonology VII, 515-546. The Hague: Mouton de Gruyter.

IPDS 1994. The Kiel Corpus of Read Speech, vol. 1, CD-ROM 1. IPDS 1994-1997. The Kiel Corpus of Spontaneus Speech, vol. 1-3, CD-ROM 2-4. Kiel: Institut für Phonetik und digitale Sprachverarbeitung.

Ramus, F., Nespor, M. and Mehler, J. 1999. Correlates of linguistic rhythm in the speech signal. Cognition 73, 265-292.

Russo, M. and Barry, W.J. 2004. In che misura l'italiano è 'iso-sillabico'? Una comparazione quantitativa tra l'italiano e il tedesco. In D'Achille, P. (ed.), Generi, Architetture e forme testuali, 387-401. Firenze, Cesati.

Russo, M. and Barry, W.J. 2008. Isochrony reconsidered. Objectifying relations between Rhythm Measures and Speech Tempo. In Barbosa P., Madureira, S. and Reis C., Proc. of 4th Conference on Speech Prosody 2008, Campinas, May 6-9, 2008, Brazil, cd rom. 